\title{
Comparative Isolation of Escherichia coli 0157:H7 from Diarrhoeic and Non-Diarrhoeic Children in Selected Communities in Cross River State, Nigeria
}

\author{
Nfongeh Joseph Fuh ${ }^{1}$, *, Owoseni Mojisola Christiana ${ }^{1}$, Upla Peter Uteh ${ }^{1}$, Odonye Dauda Dantani ${ }^{1}$, \\ Akharenegbe Pedro ${ }^{1}$, Fadayomi Victor Kolawole ${ }^{1}$, Uchenwa Mercy Ogechi ${ }^{2}$ \\ ${ }^{1}$ Department of Microbiology, Faculty of Science, Federal University, Lafia, Nigeria \\ ${ }^{2}$ Department of Microbiology, Faculty of Biological Sciences, University of Calabar, Calabar, Nigeria
}

Email address:

dejoeman@yahoo.com (N. J. Fuh)

${ }^{*}$ Corresponding author

\section{To cite this article:}

Nfongeh Joseph Fuh, Owoseni Mojisola Christiana, Upla Peter Uteh, Odonye Dauda Dantani, Akharenegbe Pedro, Fadayomi Victor Kolawole, Uchenwa Mercy Ogechi. Comparative Isolation of Escherichia coli 0157:H7 from Diarrhoeic and Non-Diarrhoeic Children in Selected Communities in Cross River State, Nigeria. Advances in Bioscience and Bioengineering. Vol. 6, No. 2, 2018, pp. 23-29. doi: 10.11648/j.abb.20180602.12

Received: June 10, 2018; Accepted: July 14, 2018; Published: August 15, 2018

\begin{abstract}
Escherichia coli O157:H7 has been considered an emerging foodborne pathogen causing severe diarrheal disease globally especially among children under the age of five years in Sub-Saharan Africa. This study was aimed at conducting a comparative study on the rate of isolation of Escherichia coli $\mathrm{O} 157: \mathrm{H} 7$ from diarrhoeic and non- diarrhoeic children in selected communities in Cross River State, Nigeria. Stool samples were collected from children under the age of five yrs and the pathogen isolated and identified using standard microbiological and biochemical procedures. Serological analysis to detect E. coli 0157:H7 serotype was carried out using Enzyme-linked immunosorbent assay (ELISA) and anti-rabbit H7 latex serum agglutination techniques. Out of 367 diarrhoeic children sampled, $70(19.07 \%)$ were positive for E. coli 0157:H7 and the prevalence differed significantly $(p<0.05)$ with the control. The prevalence of E. coli 0157:H7 between diarrhoeal $(19.07 \%)$ and non-diarrhoeal $(1.39 \%)$ cases also differed significantly $(p<0.05)$ among the sampling areas. Diarrhoeric children below the age of one year had significantly highest prevalence of $26.83 \%$ at $p<0.05$ though no significant relationship between the sex of the children and the rate of infection with the organism was observed. Children diarrhoaeic stool therefore serves as a major vehicle in the domestic transmission of Escherichia coli O157:H7. Improved personal hygiene and environmental sanitation among parents and care givers can reduce the spread of diarrheal disease caused by this pathogen amongst children under the age of five years.
\end{abstract}

Keywords: Escherichia coli O157:H7, Childhood Diarrhoea, Nigeria

\section{Introduction}

In developing countries, diarrhea is one of the main causes of morbidity and mortality in children younger than 5 years of age [1]. Twenty-one percent of childhood mortality in children younger than 5 years of age in these countries is associated with diarrheoa, resulting in 2.5 million deaths per year [2]. Diarrhea kills more young children than do AIDS, malaria and measles combined $[3,4]$.

The different diarrheal syndromes can be caused by bacterial, viral and parasitic infections of either single or multiple aetiology [5]. Escherichia coli, is documented as the most-studied bacterium, which colonizes the gastrointestinal tract of most warm-blooded animals within hours or a few days after birth [6]. Escherichia coli $\mathrm{O} 157: \mathrm{H} 7$ is a serotype of the bacterial species Escherichia coli and is one of the Shiga toxin-producing types [4]. Escherichia coli O157:H7 is an important food borne pathogen of public health importance $[7,8]$ Food pathogens cause more than threehundred diseases from simple diarrhea to death [9]

Infection with E. coli $\mathrm{O} 157: \mathrm{H} 7$ follows ingestion of 
contaminated food or water, or oral contact with contaminated surfaces [10] The consumption of contaminated and raw food, including raw milk aids transmission [11]. The World Health Organization in 2008 stated that the highest number of diarrheagenic E. coli isolated in their study belonged to the O157:H7 serogroup [4]. In developing countries, the burden of diarrhoea and its mortality in children still exists. Africa and Asia account for $80 \%$ of children deaths due to diarrhoea with Nigeria ranking second with an estimated annual total of 151,700 child deaths due to diarrhoea [12]. This comparative study was hereby designed to analyze Escherichia coli 0157:H7 from diarrhoeic and non- diarrhoeic children in selected communities in Cross River State, Nigeria.

\section{Materials and Methods}

\subsection{Study Area}

This research was carried out in selected highly populated communities in Cross River State. The State is located in the Niger Delta Region, Southern Nigeria and it occupies an area of $299,10 \mathrm{~km}^{2}$ with an estimated population of 3,920,208 as at 2006 Nigeria population Census [13]. It is bounded to the North by Benue State, to the West by Enugu and Abia States, to the East by the Republic of Cameroon and to the South by Akwa Ibom State and the Atlantic Ocean

\subsection{Sampling Design}

The study area was mapped out according to political senatorial districts i.e Northern, Central and Southern Districts. Each senatorial district was further mapped out into two sampling areas (SA) each comprising of two most populated Local Government Areas (LGAs) namely SA1 (Obudu/Bekwarra LGAs), SA2 (Ogoja/Yala LGAs), SA3 (Ikom/Boki LGAs), SA4 (Obubra/Yakurr LGAs), SA5 (Akamkpa/Biase LGAs) and SA6 (Calabar Municipality/Akpabio LGAs)

\subsection{Ethical Approval}

Ethical approval was obtained from the Ethical Review Committee of the various health institutions. The parents/guardians were asked for and provided informed consent for participation of their children / wards in this study.

\subsection{Environmental/Human Factor Investigation on Escherichia coli 0157:H7 Transmission}

A standard structured questionnaire was issued to parent/guardian of each subject to obtain vital demographic, clinical and environmental data such as age, sex, occupation of parents, feeding habits sources of drinking water, diarrhoeal type, animal contact etc. of the subject.

\subsection{Sample Collection}

Stool specimens were obtained from children of both sexes age between $0-5 y r s$ that had not been on any antibiotic treatment for at least 48 hours prior to sample collection. A total of 309 fresh diarrhoeric samples with the following distribution:69, 60, 63, 65, 52 and 58 collected from sampling areas $1,2,3,4,5$, and 6 respectively and 216 nondiarrhoeric samples (36 from each sampling area) were collected from both out-patients and in-patients in pediatric wards and those on post-natal visits. Hospitals and Health Centers located within each sampling area were used as referral centers.

A case of diarrhoea was defined as a history of more than one stool of liquid consistency or three or more stools of loose consistency, during the previous $24 \mathrm{hrs}$. Severe diarrhoea was defined as more than three watery stools plus signs of dehydration (reduced consciousness, sunken eyes, dryness of mucous membranes, thirst and skin turgor) [14]. Samples were collected in clean, leak-proof screw-capped plastic containers containing Amies transport medium. All samples collected were transported within $24 \mathrm{hrs}$ in an ice cold box at $4^{\circ} \mathrm{C}$ to the microbiology laboratory for analysis.

\subsection{Sample Processing}

About $1.0 \mathrm{ml}$ of each stool samples suspension from transport medium was introduced in to $10 \mathrm{ml}$ of buffered peptone water containing cefixime $(0.05 \mathrm{mg} / \mathrm{l})$ and vancomycin $(8.0 \mathrm{mg} / \mathrm{l})(\mathrm{BPW}-\mathrm{CV})$ and vigorously vortexed for 30 seconds to homogenize the mixture. It was then incubated at $37^{\circ} \mathrm{C}$ for $24 \mathrm{hrs}$ for enrichment.

The Enzyme-linked immunosorbent assay (ELISA) technique was used for the qualitative detection of $E$. coli 0157 antigens in all enriched samples [15]. Two drops of each sample was introduced into separate wells until all the required number of wells (excluding the control wells) were used depending on the number of enriched samples to be assayed. Two drops of the positive and negative control solutions were also dropped into their respective wells. The contents were incubated at $37^{\circ} \mathrm{C}$ for $30 \mathrm{~min}$ and 2 drops of the enzyme conjugate added to each well. After a period of 30 min incubation, the contents were washed thrice using deionized water and 2 drops of chromogen added to each with gentle shaking. The results were compared to those of the positive and negative control wells. A significant colour change to yellow indicated the presence of the E. coli 0157 antigen bound by the anti-E. coli 0157 antibodies impregnated in the wells. An optical density (OD) reading greater than 0.15 also confirmed a positive result.

All enriched samples with positive ELISA results were analysed using the standard $E$. coli $0157: \mathrm{H} 7$ culture technique as recommended by [16]

All enriched, ELISA positive stool samples were serially diluted to $10^{-3}$ using physiological saline $(0.85 \% \mathrm{w} / \mathrm{v} \mathrm{NaCl})$. Approximately $0.1 \mathrm{ml}$ of $10^{-2}$ and $10^{-3}$ dilutions were spread plated on sorbitol MacConkey agar supplemented with cefixime $(0.5 \mathrm{mg} / \mathrm{l})$ and potassium tellurite $(2.5 \mathrm{mg} / \mathrm{l})$ (SMACCT). All cultured samples were incubated overnight at $42^{\circ} \mathrm{C}$ for $24 \mathrm{hr}$. sorbitol-negative colonies that appeared colourless to grey on SMAC-CT were considered positive for E. coli 
0157:H7. Three randomly selected suspected colonies were isolated on each plate and separately subcultured on nutrient agar slants and stored at $4^{\circ} \mathrm{C}$ in a refrigerator.

All positive colonies isolated on nutrient agar slants were further inoculated into test tubes containing $E$. coli with MUG (E. coli-MUG) medium and incubated at $42^{\circ} \mathrm{C}$ for 18 $24 \mathrm{~h}$. The broth cultures were then observed under ultraviolet (uv) light of long wavelength $(650 \mathrm{~nm})$ to detect the inability of $E$. coli $0157: \mathrm{H} 7$ to cleave MUG (about $92 \%$ of $E$. coli other than E. coli 0157:H7 produce the enzyme glucoronidase which cleaves MUG to produce a blue fluorescent product). Positive isolates were considered as those that fermented lactose (yellow broth), produced gas (collected at the tip of the immersed durham tubes) and did not produce any fluorescence. Other confirmatory biochemical tests typical to $E$ coli such as indole, methyl red, voges proskauer, citrate and lysine decarboxylase were also performed on the isolates.

Antigen typing was performed using standard E. coli 0157:H7 antisera (Difco Laboratories, Detroit, Mich.) produced from rabbits and preserved with glycerol using 1:2 dilution. Slide agglutination technique was used to test resuscitated colonies directly from sorbitol MacConkey agar (SMAC) as recommended by [3]. Colonies that agglutinated rapidly with the E. coli $0157: \mathrm{H} 7$ antisera were considered as confirmed positive $E$. coli $0157: \mathrm{H} 7$ colonies.

\section{Results}

The various percentage prevalence of E. coli $0157: \mathrm{H} 7$ in diarrhoeal and non-diarrhoeal cases from the various sampling areas are presented in Table 1. The highest percentage prevalence of $30.77 \%$ from diarrhoeal cases was obtained in sampling area 4 (Obubra/Yakurr Local Government Areas), followed by sampling area 3 (Ikom/Boki Local Government Areas) with $25.40 \%$ while the least value of $11.54 \%$ was obtained in sampling area 5 (Akamkpa/Odukpani Local Government Areas). Significant difference $(p<0.05)$ was observed in the prevalence of $E$. coli 0157:H7 in diarrhoeal cases among the various sampling areas. Non-diarrhoeal samples had prevalence of $2.78 \%$ from
SA1 (Obudu/Bekwarra LGAs), SA4 (Obubra/Yakurr LGAs) and SA6 (Calabar Municipality/Akpabio LGAs) while no pathogen was isolated from SA2, SA3 and SA5. No significant difference $(P>0.05)$ was observed in the percentage prevalence in non-diarrhoeal cases while the values between the diarrhoeal and non-diarrhoeal cases differed significantly $(P<0.05)$.

Male diarrheal samples had highest prevalence of $28.57 \%$ obtained from sampling area 4 followed by sampling area 3 with $21.21 \%$. The least percentage was $10.34 \%$ obtained from sampling area 2 while the overall percentage prevalence was $17.51 \%$. In female diarrheal cases, the highest percentage prevalence was $30.00 \%$ obtained from sampling area 3 followed by $27.27 \%$ from sampling area 4 . The least percentage of $10.00 \%$ was obtained from sampling area 5 while the overall percentage prevalence obtained was $18.95 \%$. No significant difference $(p>0.05)$ was observed in the percentage prevalence between both sexes as presented in table 2 .

The occurrence of E. coli $0157: \mathrm{H} 7$ in diarrhoeic children according to various age range is presented in Table 3 . The age range $<1$ year had the highest percentage prevalence of $26.83 \%$ while the age range $3-4$ yrs had the least value of $16.78 \%$. The percentage prevalence of E. coli $0157: \mathrm{H} 7$ among the various age ranges was significantly different $(P<0.05)$.

In the evaluation of the impact of environmental and behavioural practices by diarrhoeic children in the transmission of $E$. coli $0157: \mathrm{H} 7$, environmental factors considered with high frequency of occurrence include; drinking water (surface water: $72.86 \%$ ), toilet facility (open: $62.86 \%$ ) and animal contact (ruminants: $78.57 \%$ ). Behavioral practices that obtained high frequencies of occurrence include eating habits (home dishes: $92.86 \%$ ), Occupation of parent/guardians (farming: 77.14\%), parent /guardians education background (none: 44.29\%) and diarrhoeal macroscopy (bloody: $81.43 \%$ ). The various frequencies of occurrence among all the factors considered had significant differences at $p<0.05$. Table 4 shows the frequency of occurrence of each factor considered while a sample of the structured questionnaire used to obtain the data.

Table 1. Prevalence of Escherichia coli 0157:H7 in diarrhoeal and non-diarrhoeal samples from various sampling areas.

\begin{tabular}{lllll}
\hline $\begin{array}{l}\text { Sampling Areas } \\
\text { oeal }\end{array}$ & $\begin{array}{l}\text { Total No. diarrhoea of } \\
\text { samples }\end{array}$ & $\begin{array}{l}\text { No. of positive diarrhoeal } \\
\text { samples (\%) }\end{array}$ & $\begin{array}{l}\text { No. of non-diarrhoeal } \\
\text { samples }\end{array}$ & $\begin{array}{l}\text { No. of positive non-diarrh } \\
\text { samples (\%) }\end{array}$ \\
\hline SA1 & 69 & $13(18.84)$ & 36 & $1(2.78)$ \\
SA2 & 60 & $7(11.67)$ & 36 & $0(0.00)$ \\
SA3 & 63 & $16(25.40)$ & 36 & $0(0.00)$ \\
SA4 & 65 & $20(30.77)$ & 36 & $1(2.78)$ \\
SA5 & 52 & $6(11.54)$ & 36 & $0(0.00)$ \\
SA6 & 58 & $8(13.79)$ & 216 & $1(2.78)$ \\
Total & 367 & $70(19.07)$ & & $3(1.39)$ \\
\hline
\end{tabular}

Table 2. Prevalence of Escherichia coli 0157:H7 in diarrhoeic samples from children according to various sexes.

\begin{tabular}{|c|c|c|c|c|}
\hline \multirow{2}{*}{ Sampling Area } & \multicolumn{2}{|l|}{ Male } & \multicolumn{2}{|l|}{ Female } \\
\hline & No. of samples & No. of positive samples (\%) & No. of samples & No. of positive samples $(\%)$ \\
\hline SA1 & 32 & $5(15.63)$ & 37 & $8(21.62)$ \\
\hline SA2 & 29 & $3(10.34)$ & 31 & $4(12.9)$ \\
\hline SA3 & 33 & $7(21.21)$ & 30 & $9(30.00)$ \\
\hline
\end{tabular}




\begin{tabular}{lllll}
\hline \multirow{2}{*}{ Sampling Area } & Male & Female & No. of positive samples (\%) \\
\cline { 2 - 5 } & No. of samples & No. of positive samples (\%) & No. of samples & $9(27.27)$ \\
\hline SA4 & 28 & $8(28.57)$ & 33 & $3(10.00)$ \\
SA5 & 25 & $4(16.00)$ & 30 & $4(14.29)$ \\
SA6 & 30 & $4(13.33)$ & 28 & $36(18.95)$ \\
Total & 177 & $31(17.51)$ & 190 & \\
\hline
\end{tabular}

Table 3. Prevalence of Escherichia coli 0157:H7 in diarrhoeric samples from children in study area according to age range.

\begin{tabular}{llll}
\hline Age (yrs) & No of samples & No of positive samples & Prevalence (\%) \\
\hline$<1$ & 41 & 11 & 26.83 \\
$1-2$ & 67 & 15 & 22.39 \\
$3-4$ & 143 & 24 & 16.78 \\
5 & 116 & 20 & 17.24 \\
Total & 367 & 70 & $\mathrm{p}<0.05$ \\
\hline
\end{tabular}

Table 4. Impacts of environmental and behavoural practices on the transmission of Escherichia coli 0157:H7 in diarrhoeic stool from children in the study area.

\begin{tabular}{|c|c|c|c|c|c|c|c|c|}
\hline \multirow{3}{*}{ Factors } & \multicolumn{6}{|c|}{ sampling area } & \multirow{3}{*}{$\begin{array}{l}\text { Total } \\
N=70\end{array}$} & \multirow{3}{*}{$\begin{array}{l}\text { Frequency of } \\
\text { occurrence }(\%)\end{array}$} \\
\hline & SA1 & SA2 & SA3 & SA4 & SA5 & SA6 & & \\
\hline & $\mathrm{N}=13$ & $\mathrm{~N}=7$ & $\mathrm{~N}=16$ & $\mathbf{N}=\mathbf{2 0}$ & $\mathrm{N}=6$ & $\mathrm{~N}=\mathbf{8}$ & & \\
\hline \multicolumn{9}{|l|}{ Environmental } \\
\hline \multicolumn{9}{|l|}{ 1. DRINKING WATER * } \\
\hline Surface & 11 & 7 & 10 & 12 & 7 & 4 & 51 & 72.86 \\
\hline Spring & 2 & 1 & 2 & 2 & 1 & 2 & 10 & 14.29 \\
\hline \multirow[t]{2}{*}{ Borehole } & 3 & 1 & 5 & 7 & 1 & 2 & 19 & 27.14 \\
\hline & & & & & & & & $p<0.05$ \\
\hline \multicolumn{9}{|l|}{ 2. TOILET FACILITY * } \\
\hline Open & 9 & 5 & 11 & 13 & 4 & 2 & 44 & 62.86 \\
\hline Pit & 4 & 2 & 4 & 9 & 2 & 5 & 26 & 37.14 \\
\hline \multirow{2}{*}{ Water system } & 0 & 0 & 1 & 0 & 0 & 1 & 2 & 2.86 \\
\hline & & & & & & & & $p<0.05$ \\
\hline \multicolumn{9}{|l|}{3 ANIMAL CONTACT * } \\
\hline Ruminants & 12 & 0 & 13 & 17 & 3 & 3 & 23 & 78.57 \\
\hline Pigs & 2 & 5 & 4 & 5 & 2 & 0 & 13 & 18.57 \\
\hline Dogs & 5 & 0 & 4 & 6 & 1 & 1 & 21 & 30.00 \\
\hline Cats & 1 & 3 & 1 & 2 & 4 & 0 & 7 & 10.00 \\
\hline Chicken & 10 & 1 & 14 & 16 & 3 & 2 & 50 & 71.43 \\
\hline \multirow[t]{2}{*}{ None } & 0 & 6 & 0 & 2 & 0 & 4 & 6 & 8.57 \\
\hline & & & & & & & & $p<0.05$ \\
\hline \multicolumn{9}{|l|}{ Behavioural Practices } \\
\hline \multicolumn{9}{|l|}{ 1. EATING HABITS * } \\
\hline Exclusive breast feeding & 1 & 0 & 1 & 1 & 0 & 1 & 4 & 5.71 \\
\hline Home dishes & 12 & 7 & 14 & 18 & 6 & 7 & 65 & 92.86 \\
\hline Hawkers & 6 & 4 & 11 & 17 & 4 & 5 & 47 & 67.14 \\
\hline Restaurant & 2 & 2 & 5 & 11 & 2 & 6 & 8 & 40.00 \\
\hline \multirow[t]{2}{*}{ Infant formulas } & 1 & 2 & 4 & 3 & 1 & 0 & 2 & 15.71 \\
\hline & & & & & & & & $p<0.05$ \\
\hline \multicolumn{9}{|c|}{ 2. OCCUPATION OF PARENTS/GUARDIAN* } \\
\hline Farming & 1 & 0 & 1 & 2 & 0 & 1 & 5 & 7.14 \\
\hline Civil (office) service & 11 & 6 & 14 & 17 & 4 & 2 & 54 & 77.14 \\
\hline Business & 6 & 2 & 5 & 6 & 2 & 5 & 26 & 37.14 \\
\hline \multirow[t]{2}{*}{ Artisans } & 2 & 1 & 2 & 3 & 0 & 1 & 9 & 12.86 \\
\hline & & & & & & & & $p<0.05$ \\
\hline \multicolumn{9}{|c|}{ 3. PARENTS/GARDIAN EDUCATION BACKGROUND } \\
\hline Primary & 4 & 2 & 9 & 7 & 2 & 2 & 22 & 31.43 \\
\hline Secondary & 2 & 1 & 1 & 4 & 1 & 3 & 12 & 17.14 \\
\hline ertiary & 2 & 0 & 1 & 1 & 0 & 1 & 5 & 7.14 \\
\hline \multirow{2}{*}{ None } & 5 & 4 & 5 & 8 & 3 & 2 & 31 & 44.29 \\
\hline & & & & & & & & $p<0.05$ \\
\hline \multicolumn{9}{|c|}{ 4. DIARRHOEA MACROSCOPY } \\
\hline Bloody & 10 & 5 & 14 & 17 & 5 & 6 & 57 & 81.43 \\
\hline Non-bloody & 3 & 2 & 2 & 3 & 1 & 2 & 13 & 18.57 \\
\hline
\end{tabular}

$\mathrm{N}=$ No of diarrhoeal samples positive for Escherichia coli $0157: \mathrm{H} 7$

* = A sample positive for more than one factor is counted as positive for each factor 


\section{Discussion}

This study confirmed the presence of E. coli $0157: \mathrm{H} 7$ among children in selected communities in Cross River State, Nigeria. The prevalence of $E$. coli 0157:H7 between diarrhoeal (19.07\%) and non-diarrhoeal (4.17\%) cases differed significantly $(p<0.05)$ among the sampling areas. Also, the prevalence among the diarrhoeal cases had significant difference $(\mathrm{p}<0.05)$ while that for non-diarrhoeal cases was insignificant $(p>0.05)$. A Higher prevalence was obtained in sample areas (SA4 and SA3) which are within the Central Senatorial Districts with congested populations, high livestock farming and relatively low hygienic standards. Some communities in this location have been shown to be endemic to diarrhoea [17]

The prevalence of (19.07\%) of E. coli 0157:H7 among children with diarrhoeal in this study agrees with the findings of [18] who conducted a similar study from Hospitalized Children in various hospitals in South- South Nigeria with an incidence rate of 20\% for E. coli O157: H7 strains. A higher prevalence $(45 \%)$ of $E$. coli O157: $\mathrm{H} 7$ pathotypes was obtained among diarrhoea patients who were children below five (5) years in Zaria, Kaduna State, Nigeria [19]. [20] reported a lower prevalence of $5.00 \%$ among patients with diarrhoea in some parts of Plateau State, Nigeria. In a study conducted by [21] in Edo State, Nigeria, a low prevalence of $2.7 \%$ was obtained from diarrhoeic patients. In Zahedan, Islamic Republic of Iran, [22] reported that out of 322 stool samples examined from children with diarrhoea, 21 colonies of sorbitol negative $E$. coli strains $(6.5 \%)$ were isolated. Serotyping revealed 4 strains positive for $E$. coli O157: H7, out of which only $2(0.6 \%)$ strains showed positive reaction with anti-H7 and were identified as E. coli O157:H7. Discrepancies in the prevalence values from different studies may be due to differences in geographical locations. Also, [23] reported the use of Loop-mediated Geothermal Amplification (LAMP) and Whole Genome Sequencing (WGS) as current diagnostic methods for the detection of E. coli $\mathrm{O} 157: \mathrm{H} 7$ to reduce discrepancies of results due to analytical methods used.

Different reports have demonstrated that E. coli $0157: \mathrm{H} 7$ is significantly associated with childhood diarrhoea [1, 17]. This tallies with the significant difference obtained in its isolation between diarrhoeal and non-diarrhoeal cases in this study. The difference in the prevalence among diarrhoeal cases in the study areas may be due to behavioral practices by the parents or care givers. It could also be due to environmental factors.

A prevalence of $4.17 \%$ was reported from non-diarrhoeal cases in this study. This finding demonstrates that E. coli O157: H7 enteric infection can be found in asymptomatic individuals without the evidence of diarrhoea. This agrees with the findings of. [24, 25].

In relation to the sex of the children, there was no significant relationship between the sex of the children and their infection with the organism. It can be inferred from the result obtained in Table 2 that gender does not constitute a risk factor for $E$. coli $\mathrm{O} 157: \mathrm{H} 7$ infection for children under the age of five. This concurs with the findings of [26] who also reported in their studies that E. coli $\mathrm{O} 157: \mathrm{H} 7$ generally affects both sexes equally. However, [18] working with human subjects in some parts of Plateau State, Nigeria reported a significantly higher prevalence of $E$. coli $\mathrm{O} 157: \mathrm{H} 7$ in males with $3.43 \%$ higher than $1.57 \%$ in females though his study was not limited to children.

Diarrhoeric children below the age of one year had the highest prevalence of $26.83 \%$ at $(p<0.05)$. This is in agreement with [27] who reported that the infection rate of diarrhoeal $E$. coli was found to decrease with age. Lower age groups were also reported by [28], [18], [29] to have highest prevalence among human subjects from parts of Northern Nigeria. The high rate of isolation within lower age groups may be due to the fact that the immune system is still developing or exposure to unhygienic environments. Immunocompromised subjects, such as those with HIV/AIDS have also been shown to have high prevalence of E. coli O157:H7 infection [29]

Older children within the age group of 1-5 years had a lower prevalence and this may be associated with the development of immunity or loss of receptors for some specific adhesion molecules [30-32]

Table 4 shows that the source of drinking water, contact with animals and poor toilet facilities poses a great risk to diarrhoeral infections and this agrees with the report of [10] These factors have also been implicated recently with the transmission of shiga toxin-producing E. coli $\mathrm{O} 157: \mathrm{H} 7$ in Africa [33]. Water used by the inhabitants of most of the studied communities for drinking and other domestic use were observed to be mostly untreated surface water or unprotected underground water. Most households had free-ranged domestic animals and poor sewage disposal systems. The implication of these factors as risk factors in the transmission of the pathogen in this study was therefore not surprising.

\section{Conclusion}

The prevalence rate of E. coli in this study was high. The findings of this study also reveals that E. coli $0157: \mathrm{H} 7$ is responsible for infectious diarrhoea among children. Since the infection primarily occurs via fecal-oral route, food hygiene measures like consumption of pasteurized milk and drinking chlorinated water could reduce transmission rate. Personal hygiene such as the habit of hand-washing with soap and clean water after visiting toilet and before feeding the child by the mothers and caretakers will significantly reduce the spread of diarrhea caused by E. coli $\mathrm{O} 157: \mathrm{H} 7$ in children.

\section{References}

[1] Azar, D. K.; Sohella, K; Ahmed F. S; Ali A. and Ahmad S. (2016). Prevalence of Escherichia coli 0157:H7 in children with bloody diarrhea. Referring to Abuzar Teaching Hospital, Ahvaz, Iran Journal of Clinical and Diagnostic Research 10 (1):13-15.

[2] Kosek. M., Bern, C. and Guerrant, R. L. (2003). The global burden of diarrhoeal disease, as estimated from studies published between 1992 and 2000. Bull WHO. 81:197-204. 
[3] World Health Organization (2018) Escherichia coli outbreaks. W. H. O. Publication Geneva Switzerland

[4] Nfongeh J. F; Epoke, J; Antai, E. E; Ikpeme, E. M; Etim, L. B; Akeh, M. and Ekpiken, S. E. (2014). The Effects of Escherichia coli 0157:H7 lipopolysaccharide (LPS) from human, cattle and poultry isolates on haematological parameters of neonatal albino rats. European Journal of Experimental Biology 4 (1):538-542

[5] Ochoa, T. J., Salazar-Lindo, E. and Cleary, T. G. (2004). Management of children with infection-associated persistent diarrhea. Semin Paediatr Infect Dis. 15 (4):229-36.

[6] Sousa, C. P. (2006). Escherichia coli as a specialized bacterial pathogen. Revista De Biologia E Ciências Da Terra. 6 (2):341-349.

[7] Luo, Y., Cui, S., Li, J., Yang, J., Lin, L., Hu, C., Jin, S., Ye, L., Zhao, Q. and Ma, Y. (2011). "Characterization of Escherichia coli isolates from healthy food handlers in hospital", Microbial Drug Resistance, 17. 443-448.

[8] Stewardson, A. J., Renzi, G., Maury, N., Vaudaux, C., Brassier, C., Fritsch, E., Pittet, D., Heck, M., van der Zwaluw, K. and Reuland, E. A. (2014). "Extended-Spectrum $\beta$ Lactamase-Producing Enterobacteriaceae in Hospital Food: A Risk Assessment". Infection Control \& Hospital Epidemiology, 35. 375-383.

[9] Havelaar, A. H., Kirk, M. D., Torgerson, P. R., Gibb, H. J., Hald, T., Lake, R. J., Praet, N., Bellinger, D. C., De Silva, N. R. and Gargouri, N. (2015). "World Health Organization Global estimates and regional comparisons of the burden of food borne disease in 2010", PLoS Med, 12. e1001923.

[10] Greig, J, D., Todd, E. C. D., Bartleson, C. and Michaels, B. (2010). "Infective Doses and Pathen Carriage."USDA (2010) Food Safety Education Conference. pp. 19-20.

[11] Gally, D. L. and Stevens, M. P. (2017). Microbe Profile: Escherichia coli O157:H7 - notorious relative of the microbiologist's workhorse."Microbiology. 163 (1): 1-3.

[12] Okeke, I. N. (2009). Regional Review Diarrheagenic Escherichia coli in -Saharan Africa: Status, uncertainties and necessities. J Infect Dev Ctries. 3: 817-842.

[13] National Bureau of Statistics. (2012). Annual Abstract of Statistics, 2012. pp 23.

[14] Presteri, E., Zwick, R. H., Reichmann, S., Aichelburg, A., Winkler, S. \& Kremsner, P. G. (2003). Frequency and virulence properties of diarrhoeagenic $E$. coli in children with diarrhoea in Gabon. American Journal of Tropical Medicine and Hygiene.69:406-410

[15] Milley, D. G, \& Sekia, L. H., (1993). An Enzyme-linked Immunosorbent Assay-based isolation procedure for verotoxigenic E. coli. Applied and Environmental Microbiology. 59 (12):4223-4229

[16] Nfongeh, J. F., Udo, S. M. and Lennox, J. A. (2005). Impact of water availability on diarrhoeal morbidity in two contrasting communities in Cross River State, Southern Nigeria. Global Journal of Pure and Applied Sciences. 11 (3):363-366

[17] Egbule, O. S., Owhe-Ureghe, U. B. and Odih, E. E. (2016). Occurrence of Multidrug Resistance among E. coli O157:H7 Isolated from Stool Samples Obtained from Hospitalized
Children. J Prob Health 4:150.

[18] Sani, A., Onaolapo, J. A., Ibrahim, Y. K. E., Idris, H. W., Igwe, J. C. and Nworie, A. (2015). Prevalence of Escherichia coli Pathotypes among Children with Diarrhoea in Zaria, Nigeria. British Journal of Medicine \& Medical Research. 7 (1): $17-24$.

[19] Itelima, J. U., Agina, S. E., Ogbonna, A. I. and Nwaukwu, I. A. (2014). The Occurrence of Escherichia Coli Serotype O157: H7 among Humans in Some Parts of Plateau State, Nigeria. Developmental Microbiology and Molecular Biology. 5 (1): 9-20.

[20] Isibor, J. O., Afe, O. E., Regina, E. O. and Philip, O. O. (2013). Escherichia coli O157:H7-Prevalence and Risk Factors of Infection in Edo State, Nigeria American Journal of Research Communication. 3 (1): 35-49.

[21] Fard, A. H. M., Bokaeian M. and Qureishi, M. E. (2008). Frequency of Escherichia coli $0157: \mathrm{H} 7$ in children with diarrhoea in Zahedan, Islamic Republic of Iran. La Revue de Santé de la Méditerranée orientale. (14) 5: 1022-1027.

[22] Newell, D. G. and Ragione, R. M. (2018) Enterhaemorrhagic and other Shiga toxin-producing Escherichia coli (STEC): where are we now regarding diagnostic and control strategies. Transboundary and Emerging Diseases 65 Suppl 1 (57)

[23] Chapman, P. A., Siddons, C. A., Cerdan-Malo, A. T. and Harkin, NM. A. (1997). A 1-year study of Escherichia coli 0157 in cattle, sheep, pigs and poultry. Epidemiology and Infection. 119:245-250.

[24] Majowicwz, S. E; Scallan E. and Jones-Bitton A. (2014). Global incidence of Shiga toxin-producing Escherichia coli infections and deaths: a systematic review and knowledge synthesis. Foodborne Pathogens and Diseases 11 (6):447-455

[25] Su, C. \& Brandt, L. J. (1995). Escherichia coli 0157:H7 infection in humans. Annals of Internal Medicine 123:698-714

[26] Gomes, T. A., Elias, W. P., Scaletsky, I. C., Guth, B. E., Rodrigues, J. F., Piazza, R. M., Ferreira, L. C. and Martinez, M. B. (2016). Diarrheagenic Escherichia Coli. Braz J Microbiol. 47 (Suppl 1):3-30

[27] Gould, L. H., Walsh, K. A., Vieira, A. R., Herman, K., Williams, I. T., Hall, A. J. and Cole, D. (2013). "Surveillance for food borne disease outbreaks-United States, 1998-2008", MMWR Surveill Summ, 62. 1-34.

[28] Abdulaziz, H. O; Aminu, M. and Machido A (2016). Isolation and characterization of Escherichia coli 0157:H7 in Human stool samples from parts of Kaduna Metropolis, Nigeria. American Journal of Food Science and Technology 4 (5):125128

[29] Reuben, C. R. and Gyar S. D. (2015). Isolation and Antibiogram of Shiga toxin-producing Escherichia coli 0157:H7 from Diarrhoeic HIV/AIDS patients in Lafia Central Nigeria. International Research Journal of Microbiology 6 (2):20-26.

[30] Moyo, S. J., Gro, N., Matee, M. I., Kitundu, J., Myrmel, H., Mylvaganam, H., Maselle, S. Y. and Langeland, N. (2011). Age specific aetiological agents of diarrhoea in hospitalized children aged less than five years in Dar es Salaam, Tanzania. BMC Pediatr.11:19.

[31] Nataro, J. P. and Kaper, J. B. (1998). Diarrheagenic Escherichia coli. Clin Microbiol Rev. 11:142-201. 
[32] Patzi-Vargas, S., Zaidi, M. B., Perez-Martinez, I., Leon-Cen, M., Michel-Ayala, A., Chaussabel, D. and Estrada-Garcia, T. (2015). Diarrheagenic Escherichia Coli carrying supplementary virulence genes are an important cause of moderate to severe diarrhoeal disease in Mexico. PLoS Negl Trop Dis. 9 (3): e0003510.
[33] Kosek. M., Bern, C. and Guerrant, R. L. (2003). The global burden of diarrhoeal disease, as estimated from studies published between 1992 and 2000. Bull WHO. 81:197-204. 